Univerzitetska misao - časopis za nauku, kulturu i umjetnost [ISSN: 1451-3870]

Vol. 16, str. 38-46, 2017 god., web lokacija gde se nalazi rad:http://um.uninp.edu.rs

Tematska oblast u koju se svrstava rad: Društvene i humanističke nauke / podoblast: Filologija

Datum prijema rada: 13.04.2017.

UDK: 003.349(497.6)

Datum prihvatanja rada: 25.08 .2017

doi:10.5937/univmis1716038S

Pregledni rad

\title{
SRODNOSTI BOSANČICE SA GOTSKIM PISMOM IZ IV VIJEKA, TE MEZAFIJSKIM (ILIRSKIM) PISMOM IZ VI VIJEKA PRIJE NAŠE ERE
}

\author{
Bisera Suljić Boškailo \\ Internacionalni univerzitet u Novom Pazaru, Novi Pazar \\ Novi Pazar, Republika Srbija \\ bisera.suljic-boskailo@uninp.edu.rs
}

\begin{abstract}
Apstrakt
Bosančica je istovjetna sa gotskim pismom, odnosno Vulfilinim biblisko-gotskom azbukom iz IV vijeka; azbukom, koju je, po mišljenju mnogih naučnika, sastavio biskup Vulfila, kako bi Bibliju preveo na gotski jezik. Bosančica je istovjetna i sa mezafijskim pismom iz vremena prije naše ere. Mezafiska azbuka o kojoj je Momzen pisao, a kasnije o njoj nastavio veliki poznavalac ilirskog jezika i pisma Hans Krahe, datira iz 6. - 1. vijeka prije naše ere. Vulfilino gotsko-biblisko pismo je istovjetno sa mezafijskim pismom.
\end{abstract}

Kljucne reči: bosančica, gotsko pismo, mezafijsko pismo

\section{MATERIALITY AND STRUCTURE OF DEFERRED TAXES IN COMPANIES IN THE REPUBLIC OF SERBIA}

\begin{abstract}
Bosancica is identical with Gothic script, or Vulfila's Biblical-Gothic asbestos from the 4th century; an asbestos, which, according to many scholars, was compiled by Bishop Vulfila, in order to translate the Bible into the Gothic language. Bosancica is identical with the Mesophone letter from the time before our era. Mezafiska's alphabet about which Momzen wrote, and later on by her, a great connoisseur of the Illyrian language and letter of Hans Krahe, dates back to the 6th - 1st century BC. The Vulfillino Gothic script is identical with the Mesopotamian script.
\end{abstract}

Key words: bosancica, a Gothic letter, a letter of the Mesophone

\section{UVOD}

Otkud srodnost bosančice i Vulfilinog-gotsko-biblijskog pisma, te mezafijskog pisma? Vulfila je prvi gotski biskup koji je bio arijanac i koji je mnoge Gote preveo iz višeboštva na hrišćanstvo, odnosno arijanstvo. Živio je i djelovao na prostorima Balkana (bugarski dio) i borio se zajedno sa ilirskim biskupima za arijanstvo, učenje u hrišćanstvu u kojem Isus nije istovjetan sa Bogom. Umro je u Konstantinopolju 383. g. upravo boreći se za arijanstvo i za arijanski nastrojene ilirske biskupe. 
Srodnosti bosančice sa gotskim pismom iz iv vijeka, te mezafijskim (ilirskim) pismom iz VI vijeka prije naše ere

Činjenica da su ilirski biskupi poznavali, odnosno djelovali sa Vulfilom, govori da su oni najvjerovatnije učestvovali u sastavljanju Vulfiline azbuke kako bi preveo Bibliju na gotski jezik.

Pošto su Mezapi jedno od ilirskih plemena, sa balkansko-ilirkog područja, u srodstvu sa grupama ilirsko-dalmatinskih naroda, koji su prije naše ere prešli na drugu stranu Adrije (Kalabrija i Apulija) i kod kojih je pronađeno preko 300 raznih dokumenata sa njihovim pismom, koje nosi direktne korijene sa fenicijskim, a bosančica istovjetna sa tim pismom, prirodni slijed daje da je bosančica starija od Vulfilinog pisma, jer je ona na tim ilirskim prostorima živjela prije Vulfile.

U Bosanskoj piramidi sunca kod Visokog nalaze se megaliti sa pismom koje je slično mesafijskom pismu i za koje se smatra da su nastali i više od dvije hiljade godina prije nase ere.

Činjenica da mezafisko pismo, odnosno bosančica imaju sva slova koja je Vulfila koristio za svoju azbuku odnosno njegovu azbuku, govori da je ova hipoteza bliža istini od one koju današnji naučnici prezentiraju, a to je da Vulfila stvorio gotsku azbuku, odnosno sastavio je iz grčkog, latinskog i runskog pisma. Naučnici još uvijek nisu posve saglasni sa nastankom mnogih slovnih znakova kojih nema u grčkom pismu, a ima u Vulfilinom, jedni smatrajući da ih je Vulfila preuzeo iz latinskog pisma, drugi iz runskog. Mnoga rješenja tih naučničkih dilema oko Vulfilinog pisma nalazi se u bosančici, odnosno u mezafijskom (ilirskom) pismu o kojemu je najpodrobnije pisao prvi njemački nobelovac Teodor Momzen, koji je nobelovu nagradu za književnost dobio kao autor historiskih djela o Rimskom carstvu, znači kao historičar. Potpuna sličnost sva ova tri pisma govori kako se radi o jednom te istom pismu, samo sa raznim nazivima: Mezafijsko pismo je dobilo naziv po ilirskom plemenu Mezafi, gotsko pismo po germanskom plemenu Goti, a bosančica najvjerovatnije po plemenu Bosni, koje je, kako istaknuti Bošnjaci 1942. g. pišu u memorandumu Hitleru, kao Gotsko germansko pleme pod imenom „Bosni“, došlo u 3. veku sa sjevera na Balkan u tadašnju rimsku provinciju Iliriju.
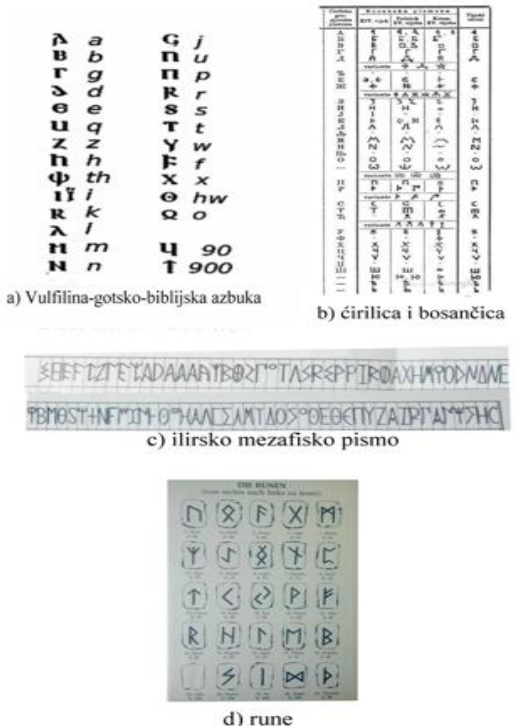


\section{UKRATKO O ILIRSKO - MEZAFIJSKOM PISMO}

Radove Njemački nobelovac Teodor Momsen, koji je za književnost dobio Nobelovu nagradu 1902. godine, i to kao historičar koji je pisao o Rimskom carstvu, jedan je među prvima koji je pisao o mezafijskom pismu (Mommsen 1850) koje je pronađeno kod prastarosjedilaca Kalabrijskog poluostrva u Italiji, smatrajući ga ilirskim pismom koje je pripadalo stanovnicima balkanskog dijela Adrije.

Mezafijsko pismo su kolonisti iz Ilirije u predantičko vrijeme donijeli u Italiju i do sada je zabilježeno i istraženo oko 300 zapisa na ovom pismu, pronađenih najviše u predjelima Kalabrije, te Apulije. Zapisi datiraju iz VI vijeka prije naše ere pa do I. vijeka našeg mjerenja vremena i većinom se radi o zapisima nadgrobnih spomenika, kao i onim na vaznama, oruđima i novčanicama. Najćešće su to lična imena u genitivu ili nominativu, i samo u par slučajeva imamo kratke tekstove od po dvije-tri riječi. Originali ovih tekstova su u većini slučajeva nestali. Ostale su samo kopije.

Mezafijski zapisi najbolje daju sliku ilirske gramatike, kao i njene jezičke strukture, te dijelom ilirske kulture, mišljenja je ne samo Momzen, već i drugi naučnici, poput velikog istraživača ilirskog jezika i kulture Hansa Krae, koji mesafijsko pismo pripisuje ilirskoj kulturi, jer data jezička struktura, rječnik, te građenje riječi, gotovo do najsitnijih detalja odgovaraju ilirskom.

Ovo pismo koje je najprije Luiđi Kepola (Luigi Cepolla) pronašao i zabiljezio 1805. godine u mjestu Vaste (Basta), prije nego je original nestao ima vokale: "A", "E", "I", "O". Vokal "U" ne postoji i zato ga najčešće "O" mijenja. Od konsonanata imamo "M", "N", "R" (piše se kao „P“), "l", "P" (piše se kao П, sa malo kraćom desnom crtom), "T", "K". Konsonat "Q" se pojavljuje samo ispred "O" koje označava (,U“). Imamo dalje konsonate "B", "G" (piše se kao $\Gamma$ ), "D“ (piše se $\Delta$ ), kao i "V", koje se koristi za oznaku vokala "U". Znak "H" Ne zna se tačno da li se kao vokal ili konsonant, ili je poluvokal). Znaci "S" (piše se C), "Z", prije "T" prelazi u "Š" (dašta). Znak za „O“ često je sa i bez tačke u sredini znaka i najčesće je puno manje od ostalih slova.

U mezafskom pismu nedostaju slova: H kao vokal (Momzen ga nije pronašao, osim u falcifikatima), U (nedostaje i u latinskim riječima), $\Phi$ (nedostaje, i tamo gdje bi trebalo da se pojavi umjesto njega stoji slovo "P", naprimjer: Aprodita umjesto Afrodita), $\mathrm{X}=\chi$ (nedostaje), $\Psi$ nedostaje, $\mathrm{Y}$ (nedostaje, nalazi se samo u falcifikatima), $\Omega$ (nedostaje, srećemo ga samo u falcifikatima).

Momsen je mišljenja kako ovih 20 zvučnih znakova najbolje govore o starosti ovog alfabeta, te da se ni jedna grčka azbuka ili azbuka čiji je korijen grčki ne može se usporediti sa ovom azbukom; jer osim znakova za sade i kof, koji nedostaju, ili ih još nismo pronašli, mezafijska azbuka zaokružuje sva fenicijska slova, i samo ta. Ovom alfabetu ne samo da nedostaju mlađa $\eta \omega \psi$, nego i oba aspiranta grčkog pronalaska $\varphi, \chi$, ko i prastaro, $\mathrm{u}$ terejskom pismu nađano $v$.

Momzen navodi činjenicu kako u mezafskom alfabetu prepoznajemo čisti prastari fenicijski zvučni sistem, čija se grafička forma tek kasnije pod utjecajem grčkog modernizirala."

Ono što je tipično za ovo pismo je da pismo ide slijeva nadesno i rijetko obrnuto. Interpunkcija se nigdje ne pojavljuje i riječi nisu, ili su veoma rijetko odvojene. 
Srodnosti bosančice sa gotskim pismom iz iv vijeka, te mezafijskim (ilirskim) pismom iz VI vijeka prije naše ere

Jedan od zvučnih imena ilirskog govora i pisma u svijetu je i Hans Krahe, koji smatra da je mezafsko pismo, odnosno većina mezafskih dokumenata, koja su veoma kratka i ne malo stereotipna, te kao ostaci, u dijelovima sačuvani, daju jedan vrijedan materijal što se tiče ličnih imena, njihov zvučni sistem, sistem građe sa odgovarajućim osobenostima, formu i zvuk ilirskog dijalekta. U mezafiskim dokumentima imamo najbolje očuvanu ilirsku gramatiku i njenu sveukupnu jezičku strukturu, a kroz svoje osobenosti mi pronalazimo i dijelove ilirske kulture:

"Da se ovi dokumenti mogu pripisati ilirskim, nije nimalo sporo. U njihovom slovnom sistemu, u riječniku, u građenju riječi - do sitnih sekundarnih odstupanja - mi prepoznajemo to što ilirska lična imena daju. Uska jezička povezanost dokumenata koji su pronađeni (Apulija i Kalbrija) potvrđuju srodnost sa balkanskim naseljima Ilira kroz mnogobrojne nazive mjesta, te korjena imena. Uz to nam dolaze neprisnovene antičke vijesti koje potvrđuju da su narodi u Apuliji i Kalbriji došli sa balkansko ilirskog dijela."(Krahe 1950)

\section{UKRATKO O VULFILINOM GOTSKOM PISMU}

Poznati historičar Georg Vajc (Georg Waitz), koji je dosta osvijetlio biografiju Vulfile, smatrao je da je Vulfila 30 godina radio na prijevodu Biblije, koji je dovršio oko 370. godine. Primjerak prevoda koji se smatra veličanstvenim čudom danas možemo vidjeti u Srebrenom kodeksu Codex argenteus, koji se čuva u švedskoj Univerzitetskoj biblioteci u Upsali.
A $a \quad \mathbf{G} j$
$\begin{array}{llll}\text { B } & b & \mathbf{n} & u\end{array}$
$\begin{array}{lll} & g & \boldsymbol{\Pi}\end{array}$
a $d \quad \boldsymbol{R} r$
G $e$ s $s$
$\begin{array}{llll}\mathbf{U} & q & \mathbf{T} & t\end{array}$
$\begin{array}{lll}Z & Z & Y\end{array}$
h $h \quad$ F $f$
$\Psi$ th $\mathrm{X} x$
if $i \quad \Theta h w$
R $k \quad \mathbf{Q} o$
$\boldsymbol{\lambda}$ I
$\begin{array}{llll}\mathbf{M} & m & \mathbf{4} & 90\end{array}$
N $n \quad \uparrow 900$

Naučnici smatraju da je to bio veliki projekt. Jer da bi preveo Bibliju na gotski Vulfila je morao naprije izmisliti slova i gramatiku, te pronađe govor pogodan za prevod Biblije na gotski. Goti dotad nisu imali pismo, osim runa koje su korišćene samo kao sredstvo u magiji. Znači, grčkom biblijskom tekstu bilo je potrebno sada jedno posve novo jezičko ruho, koje je Vulfila morao iz gotskog govora da izvede, što 
je gotovo isto kao da je morao napraviti jedan veliki brod za svoj narod, i to bez alata. Vulfila je uzeo grčku verziju Biblije da prevede na gotski, iako je znao i grčki i latinski. Zašto grčku? Jedan od razloga je i taj što su u to vrijeme i najniži slojevi Gota razumjeli grčki, jer su bili u dodiru s tom kulturom. Uostalom, čak se i u jakom Rimu $\mathrm{u}$ to vrijeme koristio grčki jezik.

Mi danas nemamo taj originalni Vulfilin prevod, ali naučnici smatraju da je sačuvani primjerak prevoda Biblije na gotski gotovo u potpunosti identičan sa originalom, jer iako su stotinama godina kasnije teolozi analizirali prevod Vulfile, on se nikada nije prepravljao. Nedostatak Vulfilinog originalnog rukopisa naučnicima, međutim dosta otežava da zaokruže predstavu o tome da li je Vulfila koristio kao materijal za svoju azbuku samo grčko pismo ili je, pak, koristio i rune, te latinsko pismo. Analizom ne samo prevoda biblije, već i ostalih tekstova koji su do danas sačuvani, a koji su po svemu sudeći bili srodni Vulfilinoj azbuci i gramatici, mi danas imamo Vulfilinu azbuku koja sadrži 27 znakova, od kojih su dva znaka (18. i 27.) za brojeve bez fonetske vrijednosti.

Smatra se da Vulfilin alfabet ne predstavlja izum kao takav već je transformacija i prilagođavanje starijeg alfabetskog materijala. Na to ukazuju između ostalog oblik i redoslijed slova i njihovo korišćenje kao brojčanih znaka. Dok su najstariji istraživači grčki alfabet smatrali jedinstvenom osnovom Vulfilinih slova, priključeni su kasnije kao izvori za njegovu azbuku i latinski alfabet i gotske rune. Učešće ova tri alfabetska sistema u Vulfilinom alfabetu je sa više strana različito procijenjeno.

Većina naučnika je mišljenja da je Vulfila većinu slovnih znaka za svoju azbuku uzeo iz grčkog pisma. Međutim za slovne forme za „h“, „,““, „s“ naučnici smatraju da su preuzeta iz latinske azbuke. Kod znaka za „f“ nisu posve jedinstveni, te jedan dio naučnika smatra da je , $\mathrm{F}^{\text {“ }}$ preuzet iz latinskog, drugi pak, iz runskog pisma. Mnogi su mišljenja da je Vulfila iz runskog pisma preuzeo i sljedeća slova: „p“, , ,j", „u“ „f“, „p“, i „,o“. Germansko-gotska slova „p“ (koje je slično engleskom „th“ i ,f“ fonetski posve odudaraju od grčkih slova, pa se zato smatra da su uzeta iz runa. Slovo „u“ u grčkom nije imao jednostavnog znaka, a u latinskom se „u“ lahko moglo zamijeniti gotskim znakom „,", zato se uzeo znak „o“, iz runskog pisma. (Streitberg 1905)

No, da li je tako. Mi upravo ove slovne znake kojih nema u grčkom pismu imamo u bosančici i mezafijskom pismu.

\section{BOSANČICA - GOTSKO PISMO - MEZAFSKO PISMO}

Radove U Glasniku Zemaljskog muzeja Bosne i Hercegovine iz 1889. godine, u knjizi IV, nalazi se tekst Čeha, dra Ćire Truhelke, prvog kustosa Zemaljskog muzeja BiH: "Bosančica. Prilog bosanskoj paleografiji". U tekstu Truhelka na osamnaest strana opisuje stanje pisma bosnačice, iznoseći, između ostalog, OSNOVNE RAZLIKE BOSANČICE I ĆIRILICE. (Glasnik 1889, IV)

Uspoređujući ilirsko-mesafijsko pismo, Vulfilino gotsko-biblijsko pismo sa Truhelkinim prikazom bosančice i ćirilice zaključujemo sljedeće:

1. Sva slova koja imamo u ilirsko-mesafijskom pismu imamo i u bosančici. 
Srodnosti bosančice sa gotskim pismom iz iv vijeka, te mezafijskim (ilirskim) pismom iz VI vijeka prije naše ere

2. Sve slovne znakove koje imamo u ćirilici, a nemamo u bosančici, nemamo ni u ilirsko-mezafijskom pismu. Ovdje se radi o desetak i više slova, što je velika razlika i što govori da je ćirilica najvjerovatnije nastala puno kasnije od bosančice.

3. Slova koja Momzen nabraja da nedostaju u mezafijskoj azbuci nedostaju i u bosančici. Posebno bih istakla znak za slovo F ( $\Phi)$ za koje Momzen kaže da nedostaje u mezafijskom, te tamo gdje bi trebalo da se pojavi, stoji P. To isto imamo i u bosančici. Truhelka o slovu "F u bosančici kaže:

„Značajno je za bosančicu kao prostonarodno pismo, da nema znaka za glas Ф. Taj je glas tugj slovjenskom jeziku, ne može se naći ni u jednoj riječi slovjenskoga korijena, a narod će se i kod tugjih riječi otimati izgovoru glasa $\Phi$. Tako će u Lici i gornjoj Krajini seljak reći „vajda“ a ne „fajda“, „varba“ a ne „farba“, a Bošnjak će Varešanin izgoarati „Pra Pranjo, Pilip“ umjesto „Fra Franjo, Filip.“

Truhelka pretpostavlja da je u ćirilici i glagoljici koje imaju ovo slovo, došlo iz grčkog pisma. Mi se ovdje moramo zapitati - zašto onda ovo slovo nije došlo iz grčkog i u bosančici? Zanimljivo je da slova „Ф“ nemamo ni u Vulfilinoj azbuci. Ovo je veoma važna činjenica koja potvrđuje našu tezu o srodnosti ova tri pisma.

4. Usporedimo li slova Vulfiline gotske azbuke sa mezafijskim pismom, vidjećemo da Vulfilina azbuka sadrži sva slova mezafijskog pisma, ali i slova koja Momzen nabraja da nije pronašao u mezafijskom pismu i koja je označio da nedostaju. Znači, razlika između Vulfilinog pisma i bosančice leži upravo u slovima koja nedostaju mezafijskom pismu, te ih i kod bosančice ne susrećemo, što navodi da je bosančica u tješnjihoj srodnosti sa mezafiskim pismom nego sa Vulfilinim, odnosno da je starija od Vulfilinog pisma.

5. Usporedimo li znakove mezafijskog pisma sa starim runskim pismom zapazićemo da tu ne nalazimo runskih znakova. Ali, usporedimo li bosančicu i gotsko pismo sa starim ili novim runskim pismom, zapazićemo da i kod bosančice i kod gotskog pisma imamo nekoliko runskih znakova. Radi se o runama koje označavaju velika gotska božanstva. Kod bosančice imamo i slovo Ж, koje u runama označava rječnu ribu, a koja je kasnije bila i monogram Isusa. Ovdje se sa razlogom trebamo upitati, zašto u mezafijskom pismu nema runa, a u bosančici i u Vulfilinom pismu ima? Odgovor ćemo vjerovatno naći u tome što je mesafijsko pismo mnogo starije i od runa i od Vulfilinog pisma, a i od bosančice koja se vjerovatno sa vremenom i dolaskom drugih naroda, posebno Gota, odnosno plemena "Bosni" malo i sama promijenila.

6. Bosančica se nije istovremeno razvijala kad i ćirilica, jer da jeste ona bi kao i ćirilica našla nove znake za pojedine glasove koji su bili različiti od grčkih? Kod ćirilice nalazimo gotovo pa još pola azbuke, bez onih 15 drugih ćirilićnih znakova koje smo imali ranije u ćirilici i koji su odbačeni! Zašto kod bosančice nemamo kao u ćirilici novih dodatih znakova? Odgovor je jednostavan. Samo nešto što je originalno se ne mijenja. Sve što je novije može da se promijeni u ovolikoj mjeri kao i ćirilica, ali stari alfabet kao što je bosančica - ne!

7. Upravo tamo gdje leži razlika između bosančice i ćirilice, bosančica i gotsko pismo imaju sličnosti. Radi se, znači, o gotskim slovima koja su pomišljenju naučnika preuzeta ili iz latinskog ili iz runskog pisma. I ne samo da se u Vulfilinoj azbuci kod ovih znakova nešto dešava, nego i u bosančici. Iz kratkog Truhelkinog analitičkog pregleda vidimo da u bosančici znaka za ,j" gotovo da i nema, ili ga ima samo u tabeli 
do XVI vijeka. Znak za vokal „u“ se u bosančici piše kao izvrnuta runa za znak „,“, a „, $\varphi$ “ gotovo da ne postoji. Uz to u gotskom pismu i bosančici se „R“ piše često kao u mezafijskom pismu (sa kosom kracom crtom), a u bosančici i kao "P" ili sa uspravnom crtom i stomakom na sredini „,", znak koji je sličan gotskom znaku, znači nešto između „pb“. Usto u bosančici vidimo da je znak "C" za slovo "S".

O čemu se ovdje radi? Stari grčki autori su nazvali Vulfilu pronalazačem gotske azbuke. No, da li je baš to tačno?

Nakon ovih očitih sličnosti bosančice i Vulfilinog pisma, čovjek ne može a da se ne zapita, da li je možda Vulfila poznavao bosansko pismo kroz ilirske biskupe, te bosančicu uzeo za prevod Biblije? Smjela tvrdnja koja, međutim, nije nemoguća, ako znamo da se Vulfila družio sa ilirskim biskupima - arijanima, i ako znamo da je sa prostora današnje Bosne ilirsko pleme Japyda, od kojih su nastali Mezapi, koji su iz Ilirije u VII ili VI vijeku prije naše ere nastanili Kalabrijsko i Apulijsko poluostrvo ponijevši sa sobom svoje pismo koje je kasnije nazvano „mezafijsko pismo“, pismo o kojem se malo zna, ali koje, naponjem ponovo, nalazimo danas na megalitima u Bosanskoj piramidi sunca, odnosno tunelima Ravne u Visokom, kao i na nekim stećcima.

Na kraju - da li je slučajno da bosančica upravo ima u svojoj azbuci slovne znake koje Vulfila nije uzeo iz grčkog i koje smatraju da je možda uzeo iz runskog ili latinskog pisma? Ne zaboravimo da je runsko pismo bilo magijsko pismo, odnosno pojedini znakovi su imali svete magične moći jer su bila oznake i za germanskogotske bogove. Ako se to višeboštvo trebalo odbaciti i preći na hrišćanstvo, zašto bi se unosila runska slova u novu vjeru? Da je Vulfila sam sklapao gotsku azbuku i da je htio da se posve zaboravi ranije gotsko pagansko vjerovanje, onda on ne bi uzeo ta slova iz runa. Mnogo u ovome nam govori da ih on ipak nije preuzeo iz runa, već neko drugi ko je, ako ništa drugo, a ono pokušao da napravi novu azbuku pogodnu za hrišćane Gote, gdje bi se zadržalo i nešto od svoje stare vjere. Veoma specifičan je znak „F “, koji kod Germana označava moćno božanstvo „Fehu“, kojeg se narod veoma bojao. Veoma ozbiljno pitanje je zašto Vulfila nije uzeo i to slovo iz grčke azbuke. Hm. Ćirilica, pa čak i glagoljica u kojoj su sva slova izvornog porijekla, uzima za znak „F“ grčki oblik. Vulfila to ne radi. Zašto se ovo slovo ne koristi ni u Bosni, gdje su Goti ili, pak, drugi starogermani poput Markona.

Mnogo je ovdje otvorenih pitanja, i novih puteva na čijem kraju dolazi istina. Ali sve ovo zahtijeva vojsku naučnika, ili pak rudara koji moraju otkopati zlato koje je tu, ali koje je dosta duboko zakopano.

Mi ćemo na kraju samo postaviti još pitanja $\square$ zašto bosančica ima puno manje znakova od ćirilice? Je li slučajno da bosančica ima gotovo isto onoliko znakova kao mezafijsko pismo, ili pak, Vulfilina azbuka, koja ima 25 znakova plus ova dva za broj 90, i 900, gdje se broj 90 označava znakom „Ч“, koji imamo u bosančici.

Na kraju, ne zaboravimo da mi imamo i pored ovolike sličnosti u slovnim znacima ovdje i drugih jezičkih sličnosti: Naprimjer, ono što je karakteristično za bosančicu za razliku od ćirilice, jeste skraćivanje riječi, što opet daje sličnost između Vulfilinog pisma i begovske bosančice. Kod ćirilice ima dosta izostavljanja slova, kao kratica, a kod bosančice gotovo da nema, osim kod pojedinih crkvenih riječi koje su prešle u narod ,poput riječi „bga - boga, dhom - duhom, sna - sina“ koji su pa i jedini primjeri. 
Srodnosti bosančice sa gotskim pismom iz iv vijeka, te mezafijskim (ilirskim) pismom iz VI vijeka prije naše ere

Bosanske su kratice ligature (spojevi) u potpunom smislu riječi, a nastale su na temelju istoga principa kao i rimske, tvrdi Truhelka koji dalje piše kako se završna slova jedne riječi spajaju sa početnim slovom druge, te zaključuje da se u bosančici radi o spojevima, a u ćirilici o vješto sastavljenim monogramima.

\section{ZAKLJUČAK}

Podsjetimo se da su i tu ligature i skraćenice u rukopisima relativno rijetke, te da se kontrakcije pojavljuju u svim rukopisima gdje su sveta imena. Sličnosti između ovih pisama nalazimo i kod neodvajanja riječi: u gotskim rukopisima je to strano (scriptium continua), isto kao i u tekstovima bosančice i mezafijskog pisma. Uopšte, gotski pisci popunjavaju svoje redove od početka do kraja, kao što je i u tekstovima bosančice, posebno begovske bosančice.

Sličnosti bosančice sa Vulfilinim, te mezafijskim pismom su tako prostrana i tako neispitana - zjape da se detaljno istraže, čime bi se napokon promijenilo lažno prestavljanje bosanskog pisma.

Do sada nije poznata tvrdnja da bi ilirsko-metafijsko pismo bilo pismo koje je Vulfila preuzeo kako bi stvorio azbuku za prevod biblije na gotski. Međutim, očito je da bi ovo rješenje odgovorilo na mnoga neriješena pitanja koja vijekovima zadaju naučnicima glavobolju, a tiču se toga odakle je Vulfila preuzeo neka slova, koja nije preuzeo iz grčkog pisma. Jednostavan odgovor svega je Vulfila je uzeo mesafijsko pismo, odnosno bosančicu za podlogu gotskog pisma, jer ova dva istovjetna pisma sadrže gotovo sva slova koja je Vulfila upotrijebio za svoju azbuku.

\section{BIBLIOGRAFIJA}

1. Braune, Wilhelm: Gotische Grammatik mit Lesestücken und Wörterverzeichnis, Halle 1880.

2. Ernst, Bernhard: Vulfila oder die gotische Bibel, Halle, 1875.

3. Giese, Wolfgang: Die Goten. Stuttgart 2004.

4. Glasnik Zemaljskog muzeja Bosne i Hercegovine iz 1889. godine, knjiga IV.

5. Haarmann, Harald: Weltgeschichte der Sprachen: Von der Frühzeit des Menschen bis zur Gegenwart. Heidelberg 1920.

6. Jantzen, Hermann: Gotische Sprachdenkmäler. Leipzig 1905.

7. Krahe, Hans: Die Sprache der Illyrier. Wiesbaden 1955.

8. Krahe, Hans: Die Sprache der Illyrier II. Die messapischen Inschriften und ihre Chronologie est de Carlo De Simone, Die Sprache der Illyrier II. Die messapischen Personennamen est de Jürgen Untermann. Wiesbaden 1964.

9. Krause, Wolfgang: Handbuch des Gotischen. 20. Auflage. Tübingen 2004.

10. Mommsen, Theodor: Die unteritalischen Dialekte. Leipzig 1850.

11. Waitz, Georg: Das Leben und die Lehre des Ulfilas. Hannover 1840. 


\section{RESUME}

Recall that these ligatures and abbreviations in the manuscripts are relatively rare, and that contractions appear in all manuscripts where they are holy names. Similarities between these letters are found in the absence of words: in Gothic manuscripts it is foreign (scriptium continua), as well as in the texts of the Bosnian and the Mesophone script. In general, Gothic writers fill their ranks from beginning to end, as is the case in the texts of the Bosnians, especially the Bey's Bosnians.

The similarity of the Bosnians with Vulfilin, and the Mesophone letter, are so vast and so unclear - they are gazing at a detailed investigation, which would eventually change the false representation of the Bosnian letter.

So far it is not known that the Illyrian-metaphysical letter would be a letter taken by Vulfila to create an alphabet to translate the Bible into Gothic. However, it is obvious that this solution will answer to many unresolved issues that for centuries give scientists a headache, and they are about where Vulfila took some letters, which he did not take from the Greek letter. The simple answer is that Vulfila took a mesafic letter, that is, a Bosniak for the Gothic text, because these two identical letters contain almost all the letters that Vulfila used for his alphabet. 